Check for updates

Cite this: RSC Adv., 2017, 7, 39306

Received 26th April 2017

Accepted 31st July 2017

DOI: $10.1039 / \mathrm{c} 7 \mathrm{ra04678b}$

rsc.li/rsc-advances

\section{Synthesis of phosphonic acid ring-substituted polyanilines via direct phosphonation to polymer main chains $\uparrow$}

\author{
Toru Amaya, (D) *a Izumi Kurata, ${ }^{a}$ Yuhi Inada, (D) $\dot{t}^{\mathrm{b}}$ Tomohiro Hatai $^{\mathrm{a}}$ \\ and Toshikazu Hirao ${ }^{b}$
}

Phosphonic acid ring-substituted polyanilines (PhosPANIs) were synthesized via reductive phosphonation of pernigraniline (a fully oxidized form of PANI) with $\mathrm{P}(\mathrm{OEt})_{3}$ and subsequent hydrolysis. The carbonphosphorus bond formation was suggested from ${ }^{31} \mathrm{P}$ NMR. This is the first example of direct phosphonation of PANI. The formal substitution ratio of the phosphonate to total number of phenyl rings in the polymer after the phosphonation reaction was up to $52 \%$. The repetition of the phosphonation reaction procedure gave the diethyl PhosPANI (EtPhosPANI) with 73\% substitution ratio. Hydrolysis of EtPhosPANIs afforded the desired PhosPANIs. The self-doping of the obtained PhosPANIs was clearly exhibited by ESR, XPS and UVvis-NIR absorption spectroscopy. The drop-cast films of PhosPANIs showed electrical conductive properties with a level suitable for charge dissipation materials. The developed synthetic approach is considered to be valuable as a practical method for phosphonic acid self-doped conductive PANIs.

\section{Introduction}

Polyanilines (PANIs) are widely known as some of the useful conductive polymers because of their availability and practical applicability. ${ }^{1-7}$ Unlike the other representative conductive polymers such as polyacetylenes, polythiophenes and polypyrroles, the electrical conductive properties of PANIs are induced by simple protonation doping of a PANI emeraldine base. ${ }^{1}$ It is believed that the conductive polysemiquinone radical cationic (polaronic) state is formed via reorganization of the electronic structure (Scheme 1a). ${ }^{1}$ On the other hand, PANIs cannot exhibit sufficient conductive properties only under basic conditions but also when acid doping is not sufficient. PANIs bearing covalently bonded acid moieties on the backbone can be doped without external dopants. ${ }^{8,9}$ A sulfonated PANI was demonstrated by Epstein et al. in 1990 as such a self-doped conductive PANI. ${ }^{10}$ The strong self-doping provides a property of resistance to a base. It has been reported that highly sulfonated PANI retains electrical conductive property under basic conditions (up to $\mathrm{pH}$ 12). ${ }^{\mathbf{1 1}}$ Concerning the synthesis, there are mainly two strategies to introduce an acid moiety. One is polymerization of monomer

\footnotetext{
${ }^{a}$ Department of Applied Chemistry, Graduate School of Engineering, Osaka University, Yamada-oka, Suita, Osaka 565-0871, Japan. E-mail: amaya@chem.eng.osaka-u.ac.jp ${ }^{b}$ The Institute of Scientific and Industrial Research, Osaka University, Mihoga-oka, Ibaraki, Osaka 567-0047, Japan

$\dagger$ Electronic supplementary information (ESI) available. See DOI: 10.1039/c7ra04678b

\$ Present address: Faculty of Materials Science and Engineering, Kyoto Institute of Technology, Matsugasaki, Sakyo-ku, Kyoto 606-8585, Japan.
}

possessing an acid moiety. ${ }^{12-19}$ The other is post-synthetic introduction of acid moieties to PANIs. ${ }^{\mathbf{1 0 1 1}, 20-27}$ The former may make the polymer design more flexible. However, the latter is considered to be advantageous in terms of the number of synthetic steps and the synthetic cost. As post-modifications to synthesize PANIs bearing sulfonic acid, both electrophilic $\mathrm{10}^{\mathbf{1 0 1 1 2 0 - 2 3}}$ and nucleophilic $^{24-27}$ (accompanying the reduction of the quinoid moiety) substitution reactions have been reported.

On the other hand, we have developed self-doped conducting PANIs, poly(2-methoxyaniline-5-phosphonic acid) (PMAP) ${ }^{17,19}$ and poly(2-methoxyaniline-5-phosphonic acid monoethyl ester) (PMAPE) ${ }^{18}$ which have phosphonic acid and phosphonic acid monoethyl ester, respectively, directly bonded to the main chain of PANI (Scheme 1b). ${ }^{28}$ They were synthesized by oxidative polymerization of the corresponding monomers. These are the first examples of PANI where phosphonic acid or phosphonic acid monoester directly attaches to the backbone. Differing from sulfonic acid, two acidic protons are available in phosphonic acid. The second acid moiety not used for doping would provide the features such as acid/base complexation (or salt formation) and resistance to base. The conductive property of various amine complexes of PMAP was investigated and the charge dissipation property of some PMAP/amine complexes in the electron-beam lithography was reported. ${ }^{29}$ We also found that PMAP exhibits deprotonation-induced efficient delocalization of polaron. ${ }^{30}$ Recently, salt formation of PMAP with didodecyldimethylammonium bromide was performed to give an organic solvent soluble self-doped PANI. ${ }^{31}$

The PANIs bearing phosphonic acid have attractive and unique properties as described above. On the other hand, the total 
synthetic steps of PMAP are four or five, which takes a time and cost. In this context, we focus on the phosphonation of PANI to introduce the phosphonic acid moiety because such methods seem to be one of the most practical ways to solve the above issues. However, direct phosphonation of PANIs has not been reported before. Herein, we describe the synthesis of a phosphonic acid ring-substituted PANI (PhosPANI) based on the reductive phosphonation of pernigraniline (a fully oxidized form of PANI) with
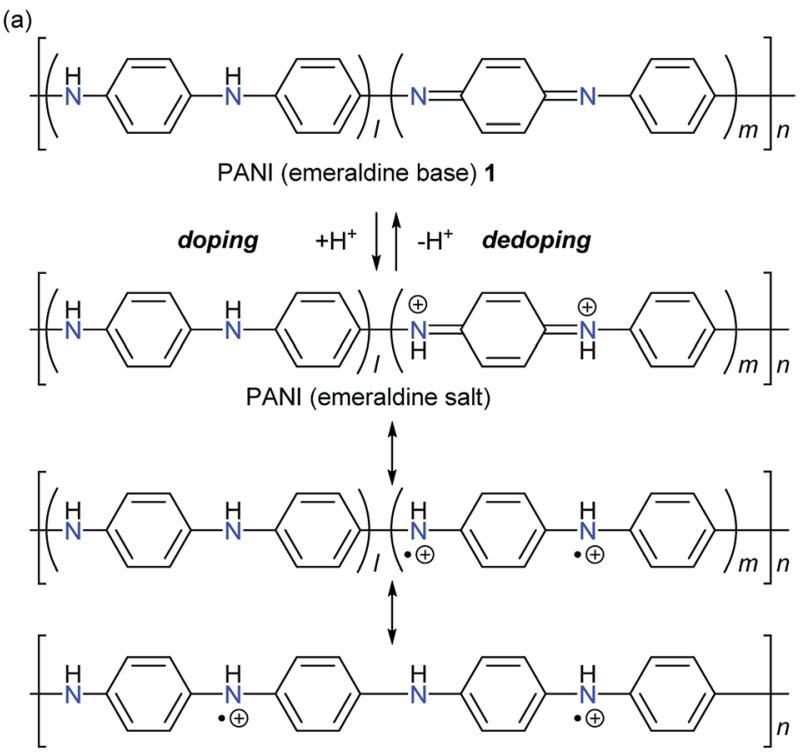

(b)

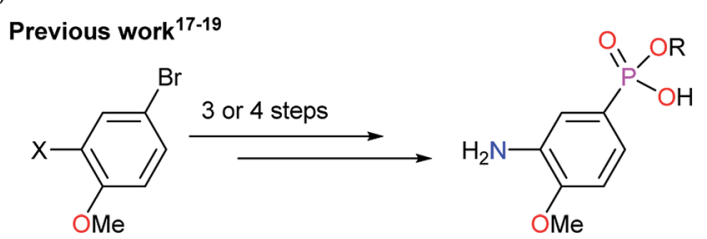

$\mathrm{X}=\mathrm{H}$ or $\mathrm{NO}_{2}$

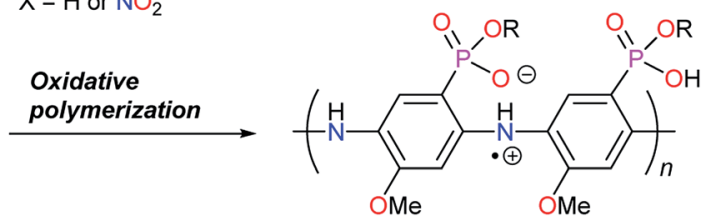

(c)

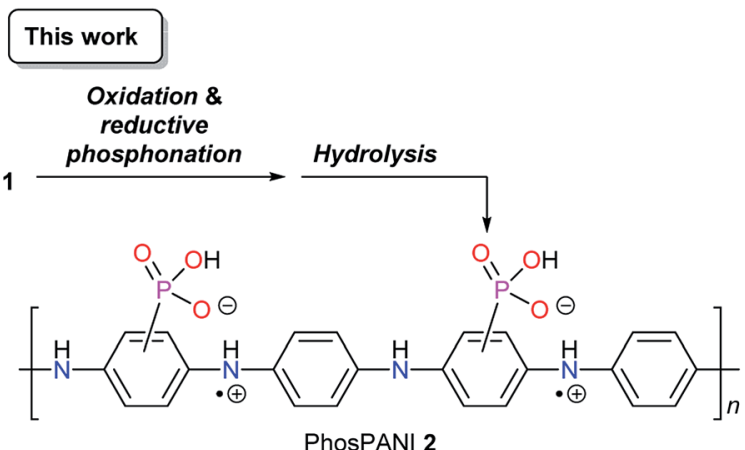

Scheme 1 (a) Doping of PANI (emeraldine base). (b) Previously reported synthetic scheme for PMAP and PMAPE in our group. (c) This work: synthetic scheme for PhosPANI 2 by oxidation and reductive phosphonation followed by hydrolysis.
$\mathrm{P}(\mathrm{OEt})_{3}$ and the subsequent hydrolysis (Scheme 1c). Its self-doping function and conductive property are also described.

\section{Experimental section}

\subsection{General}

All reagents were purchased from commercial sources. PANI was purchased from Aldrich ( $\left.M_{\mathrm{w}} 10000\right)$. Anhydrous MeCN was prepared using a Glass Contour Solvent Dispensing System. Unless otherwise noted, they were used without further purification. Preparation of PMAP is reported in our previous papers..$^{17,19}$ Elementary analyses were performed on a JSCIENCE LAB Co., Ltd MICRO CORDER (JM-10). ICP-AES analysis was carried out on a SHIMADZU ICPS-8100. Thermogravimetric analysis (TGA) were performed on a Rigaku TG8120 under $\mathrm{N}_{2}$ purge $\left(100 \mathrm{~mL} \mathrm{~min}^{-1}\right)$ at heating rate of $10^{\circ} \mathrm{C} \mathrm{min}^{-1}$. ESR spectra were taken on a Bruker ER 070 spectrometer. XPS measurements were performed on a JEOL JPS-9010MC spectrometer. The binding energies were referenced to $\mathrm{Ag} 3 \mathrm{~d}_{5 / 2}$ line $(368.2 \mathrm{eV}) .{ }^{32}$ UV-vis-NIR absorption spectra were recorded on a JASCO V-670 spectrometer. NMR spectra were recorded on a JEOL JNM-ECP 400 or Bruker Avance III spectrometer. Chemical shifts were reported in ppm on the $\delta$ scale relative to a residual solvent (DMSO- $d_{6}: \delta 2.50$ for ${ }^{1} \mathrm{H}$ NMR and $\delta 39.52$ for ${ }^{13} \mathrm{C} \mathrm{NMR} ; \mathrm{CD}_{2} \mathrm{Cl}_{2}: \delta 5.32$ for ${ }^{1} \mathrm{H}$ NMR and $\delta 53.80$ for ${ }^{13} \mathrm{C}$ $\mathrm{NMR}$ ) as an internal standard. An $85 \%$ aqueous phosphoric acid solution $(\delta 0.00$, sealed capillary) was used as an external standard for ${ }^{31} \mathrm{P}$ NMR. Infrared spectra were obtained with a JASCO FT/IR6200 spectrometer. Mass spectra were recorded on a JEOL JMS-700 spectrometer using the fast atom bombardment (FAB).

\subsection{Calculation for the formal substitution ratio of phosphonate}

Given the structure of diethylphosphonated PANI (EtPhosPANI) 3 (Scheme 2) as described in Fig. 1, formula weight (Fw) is calculated to be " $\mathrm{Fw}(3)=90.5 n+227$ ". Here, the precise ratios of quinoid and benzenoid moieties are unknown, but the absorption spectra of 3 showed a kind of typical ones for half-oxidized form of PANIs (this is described in Section 3.1). For unsubstituted aniline unit, it is assumed here that there are the same number of quinoid and benzenoid moieties in terms of averaging. The equation on the ratio of phosphorus is

$$
\operatorname{Aw}(\mathrm{P}) / \mathrm{Fw}(\mathbf{3})=\mathrm{P}(\mathrm{wt}) / \mathbf{3}(\mathrm{wt}) .
$$

Here, $\operatorname{Aw}(\mathrm{P}), \mathrm{P}(\mathrm{wt})$ and $3(\mathrm{wt})$ are defined as atomic weight of phosphorus, weight of the phosphorus and the total weight of $\mathbf{3}$, respectively. $\operatorname{Aw}(\mathrm{P})=31 . \mathrm{P}(\mathrm{wt})$ is obtained by the ICP-AES analysis. Substituting each value into eqn (1) and solving eqn (1) find the value of " $n$ ". Formal substitution ratio of phosphonate to the total number of phenyl rings in the polymer 3 $(X \%)$ can be calculated to be

$$
X=[1 /(n+1)] \times 100 .
$$

Solving eqn (2) finds the value of " $X$ ". Using thus-calculated $X$, EtPhosPANI 3 is described as EtPhosPANI $3(X \% \mathrm{P})$. 
(a) Phosphonation

I

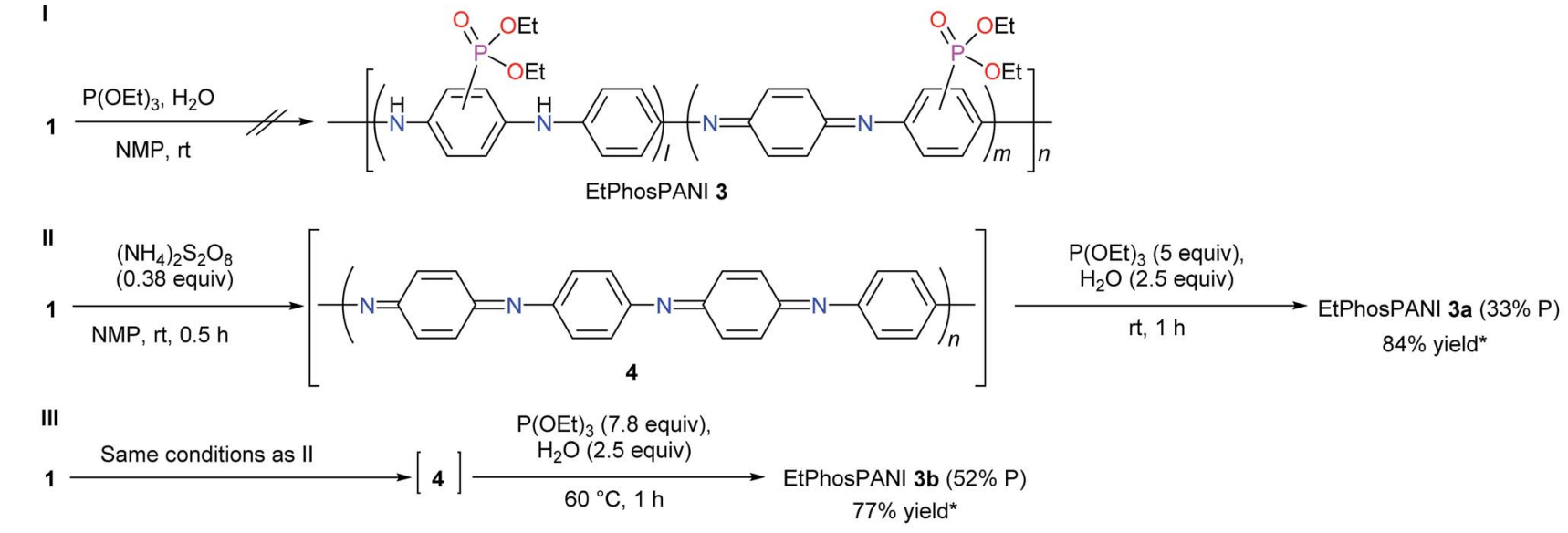

IV

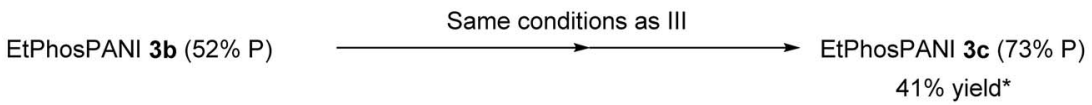

(b) Hydrolysis

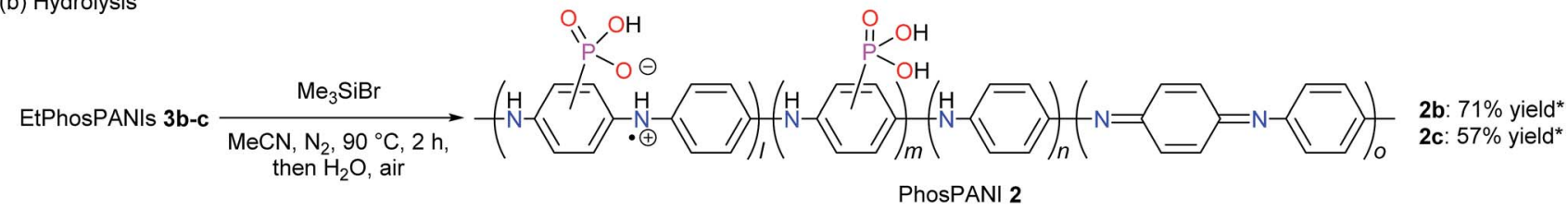

Scheme 2 (a) Phosphonation reaction to produce EtPhosPANIs 3. (b) Hydrolysis of EtPhosPANIs 3 to produce PhosPANIs 2 . *Yield [\%] = (mole of product based on an aniline unit)/(mole of substrate based on an aniline unit) $\times 100$, where mole of 3 is calculated using the molecular weight of 3 estimated from the structure given in Fig. 1. To calculate the yield of 2 formally, the structure of 2 is given as a compound that ethyl group in 3 in Fig. 1 is replaced with proton.

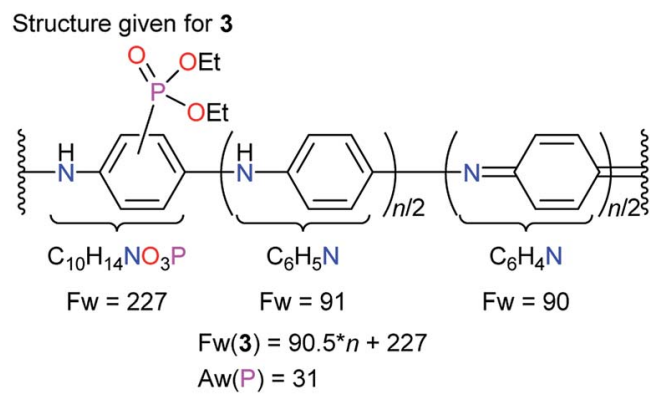

Fig. 1 Structure given for EtPhosPANI 3.

EtPhosPANI 3a. The value of concentration for phosphorus obtained from the ICP-AES analysis: $14.91 \mathrm{mg} \mathrm{L}^{-1}$; volume: 50 $\mathrm{mL}$; total weight for 3a: $9.83 \mathrm{mg}$ (it is the value after the weight of $\mathrm{H}_{2} \mathrm{O}$ included in $3 \mathbf{a}$, which was estimated by TGA, was subtracted).

$$
n=[9.83 /(14.91 \times 50 / 1000) \times 31-227] / 90.5=2.0, X=33
$$

EtPhosPANI 3b. The value of concentration for phosphorus obtained from the ICP-AES analysis: $24.78 \mathrm{mg} \mathrm{L}{ }^{-1}$; volume: 100 $\mathrm{mL}$; total weight for $\mathbf{3 b} \mathbf{b} 24.79 \mathrm{mg}$ (it is the value after the weight of $\mathrm{H}_{2} \mathrm{O}$ included in $\mathbf{3 b}$, which was estimated by TGA, was subtracted).

$$
n=[24.79 /(24.78 \times 100 / 1000) \times 31-227] / 90.5=0.92, X=52
$$

EtPhosPANI 3c. The value of concentration for phosphorus obtained from the ICP-AES analysis: $20.36 \mathrm{ppm}$; volume: 100 $\mathrm{mL}$; total weight for 3c: $17.08 \mathrm{mg}$ (it is the value after the weight of $\mathrm{H}_{2} \mathrm{O}$ included in 3c, which was estimated by TGA, was subtracted).

$$
n=[17.08 /(20.36 \times 100 / 1000) \times 31-227] / 90.5=0.37, X=73
$$

\subsection{Synthesis}

EtPhosPANI 3a (33\% P). PANI 1 (362 mg, $4.0 \mathrm{mmol}$ based on an aniline unit) was dissolved in NMP $(20 \mathrm{~mL})$ by sonication for $5 \mathrm{~min}$. To the mixture was added $\left(\mathrm{NH}_{4}\right)_{2} \mathrm{~S}_{2} \mathrm{O}_{8}(342 \mathrm{mg}, 1.5$ $\mathrm{mmol}$ ) at room temperature. After stirring for $30 \mathrm{~min}$, the deionized water $(0.18 \mathrm{~mL}, 10.0 \mathrm{mmol})$ and $\mathrm{P}(\mathrm{OEt})_{3}(3.36 \mathrm{~mL}$, $20.0 \mathrm{mmol}$ ) were added to the mixture at room temperature. After stirring for $1 \mathrm{~h}$, the reaction mixture was poured into $\mathrm{H}_{2} \mathrm{O}$ $(200 \mathrm{~mL})$. The resulting solid was collected by suction filtration. The obtained solid was added to an aqueous $0.15 \mathrm{M} \mathrm{NH}_{3}$ solution $(200 \mathrm{~mL})$ to dedope. The suspension was stirred and 
sonicated for $10 \mathrm{~min}$. The solid was collected by suction filtration. The solid was added to deionized water $(200 \mathrm{~mL})$. The suspension was stirred and sonicated for $10 \mathrm{~min}$. The solid was collected by suction filtration. The solid was added to $\mathrm{Et}_{2} \mathrm{O}(100$ $\mathrm{mL}$ ). The suspension was stirred. The solid was collected by suction filtration and dried in vacuo at $50{ }^{\circ} \mathrm{C}$ overnight to give EtPhosPANI 3a (33\% P) (456 mg, $3.36 \mathrm{mmol}, 84 \%$ yield). ${ }^{1} \mathrm{H}$ NMR (DMSO- $d_{6}, 400$ MHz) $\delta 8.80-6.45$ (br), 4.20-3.75 (br), 1.400.70 (br); ${ }^{31} \mathrm{P}$ NMR (DMSO- $\left.d_{6}, 162 \mathrm{MHz}\right) \delta 21.5-16.0$; IR (KBr) $\nu$ 3290, 2980, 2905, 1593, 1507, 1295, 1240, 1165, 1014, $968 \mathrm{~cm}^{-1}$. Anal. Calcd. for $\left(\mathrm{C}_{22.04} \mathrm{H}_{24.12} \mathrm{~N}_{3.01} \mathrm{O}_{3.54} \mathrm{P}_{1.00}\right.$, this includes 2.33 wt $\%$ of $\mathrm{H}_{2} \mathrm{O}$, which was estimated by TGA): C, 63.21; H, 5.80; N, 10.06; P, 7.40 found: C, 61.84; H, 5.80; N, 9.74.

EtPhosPANI $3 \mathbf{b}(\mathbf{5 2} \% \mathbf{P})$. The synthetic procedure is the same as that for $3 \mathbf{a}$ except the temperature $\left(60^{\circ} \mathrm{C}\right.$ for $\left.\mathbf{3 b}\right)$, see below. Amount of reagents: PANI $1(1.81 \mathrm{~g}, 20.0 \mathrm{mmol}$ based on an aniline unit), $\left(\mathrm{NH}_{4}\right)_{2} \mathrm{~S}_{2} \mathrm{O}_{8}(1.71 \mathrm{~g}, 7.5 \mathrm{mmol}), \mathrm{NMP}(100 \mathrm{~mL})$, the deionized water $(0.9 \mathrm{~mL}, 50.0 \mathrm{mmol})$ and $\mathrm{P}(\mathrm{OEt})_{3}(26.0 \mathrm{~mL}$, $155.0 \mathrm{mmol}$ ). Product 3b: $2.49 \mathrm{~g}, 15.4 \mathrm{mmol}$, 77\% yield; ${ }^{1} \mathrm{H}$ NMR (DMSO- $\left.d_{6}, 400 \mathrm{MHz}\right) \delta 8.85-6.30$ (br), 4.15-3.80 (br), 1.40-0.70 (br); ${ }^{31} \mathrm{P}$ NMR (DMSO- $\left.d_{6}, 162 \mathrm{MHz}\right) \delta 20.5-17.3$; IR (KBr) $\nu 3291$, 2934, 2904, 1593, 1507, 1295, 1238, 1164, 1017, 963, 814, 796 $\mathrm{cm}^{-1}$. Anal. Calcd. for $\left(\mathrm{C}_{15.51} \mathrm{H}_{18.98} \mathrm{~N}_{1.92} \mathrm{O}_{3.42} \mathrm{P}_{1.00}\right.$, this includes $2.39 \mathrm{wt} \%$ of $\mathrm{H}_{2} \mathrm{O}$, which was estimated by TGA): C, 58.58; $\mathrm{H}$, $6.01 ; \mathrm{N}, 8.45$; P, 9.74 found: C, 59.73; H, 5.78; N, 9.09.

EtPhosPANI 3c (73\% P). EtPhosPANI 3b (52\% P) $(215 \mathrm{mg}$, $1.33 \mathrm{mmol}$ based on an aniline unit) was dissolved in NMP (20 $\mathrm{mL}$ ) by sonication for $5 \mathrm{~min}$. To the mixture was added $\left(\mathrm{NH}_{4}\right)_{2} \mathrm{~S}_{2} \mathrm{O}_{8}(120 \mathrm{mg}, 0.53 \mathrm{mmol})$ at room temperature. After stirring for $30 \mathrm{~min}$, the deionized water $(63 \mu \mathrm{L}, 3.50 \mathrm{mmol})$ and $\mathrm{P}(\mathrm{OEt})_{3}(1.83 \mathrm{~mL}, 10.9 \mathrm{mmol})$ were added to the mixture. Then, the reaction mixture was warmed to $60{ }^{\circ} \mathrm{C}$. After stirring at $60{ }^{\circ} \mathrm{C}$ for $1 \mathrm{~h}$, the reaction mixture was poured into $\mathrm{H}_{2} \mathrm{O}(200 \mathrm{~mL})$. Because the solid did not appear, the solvent was removed by distillation in vacuo. After the most of solvent was removed, toluene $(40 \mathrm{~mL})$ was added. The mixture was sonicated for $5 \mathrm{~min}$. Then, the solvent was completely removed by heating in vacuo. To the residue was added deionized water, and the suspension was filtered to give the solid. The obtained solid was added to an aqueous $0.15 \mathrm{M} \mathrm{NH}_{3}$ solution $(200 \mathrm{~mL}$ ) to dedope. The suspension was stirred and sonicated for $10 \mathrm{~min}$. The solid was collected by suction filtration. The solid was added to deionized water (400 $\mathrm{mL}$ ). The suspension was stirred and sonicated for $10 \mathrm{~min}$. The solid was collected by suction filtration. The solid was washed with $\mathrm{Et}_{2} \mathrm{O}(200 \mathrm{~mL})$ and dried at $40{ }^{\circ} \mathrm{C}$ in vacuo overnight to give EtPhosPANI 3c (73\% P) (105 mg, $0.55 \mathrm{mmol}, 41 \%$ yield). ${ }^{1} \mathrm{H}$ NMR (DMSO- $\left.d_{6}, 400 \mathrm{MHz}\right) \delta$ 8.20-6.50 (br), 4.30-3.70 (br), 1.30-0.70 (br); ${ }^{31} \mathrm{P}$ NMR (DMSO- $\left.d_{6}, 162 \mathrm{MHz}\right) \delta 18.2-16.5$; IR (KBr) $\nu$ 3065, 1577, 1507, 1296, 1214, 1152, 1014, 942, 822, $784 \mathrm{~cm}^{-1}$. Anal. Calcd. for $\left(\mathrm{C}_{12.20} \mathrm{H}_{16.69} \mathrm{~N}_{1.37} \mathrm{O}_{3.52} \mathrm{P}_{1.00}\right.$, this includes $3.48 \mathrm{wt} \%$ of $\mathrm{H}_{2} \mathrm{O}$, which was estimated by TGA): C, 54.30; H, 6.24; N, 7.09; P, 11.48 found: C, 52.98; H, 6.03; N, 6.97.

PhosPANIs 2b and 2c (Scheme 2). A two-necked reaction vessel was dried by heating with a heat-gun in vacuo, and the atmosphere was replaced by a molecular nitrogen. To the reaction vessel were added EtPhosPANIs 3 (3b: $200 \mathrm{mg}$, $1.24 \mathrm{mmol}$; 3c: $78.6 \mathrm{mg}, 0.41 \mathrm{mmol})$, anhydrous $\mathrm{MeCN}(20 \mathrm{~mL})$ and $\mathrm{Me}_{3} \mathrm{SiBr}(3 \mathbf{b}$ :
$2.2 \mathrm{~mL}, 16.7 \mathrm{mmol}$; $3 \mathrm{c}: 1.1 \mathrm{~mL}, 8.3 \mathrm{mmol}$ ) at room temperature. The reaction mixture was warmed to $90{ }^{\circ} \mathrm{C}$. After stirring at $90{ }^{\circ} \mathrm{C}$ for $3.5 \mathrm{~h}$, the reaction mixture was poured into deionized water (300 mL). The resulting solid was collected by suction filtration. The solid was washed with $\mathrm{Et}_{2} \mathrm{O}(100 \mathrm{~mL})$ and dried at $40{ }^{\circ} \mathrm{C}$ in vacuo overnight to give PhosPANI 2 (2b: $117 \mathrm{mg}, 0.88 \mathrm{mmol}, 71 \%$ yield; 2c: $35.1 \mathrm{mg}, 0.23 \mathrm{mmol}, 57 \%$ yield). 2 b: $\mathrm{IR}(\mathrm{KBr}) \nu 3242,3065$, 1587, 1506, 1305, 1157, 1075, 989, 942, 880, $822 \mathrm{~cm}^{-1}$. 2c: IR (KBr) $\nu$ 3300, 3065, 1577, 1507, 1296, 1214, 1152, 1074, 942, 822, $784 \mathrm{~cm}^{-1}$.

Diethyl (2,5-bis(phenylamino)phenyl)phosphonate (6) and tetraethyl (2,5-bis(phenylamino)-1,4-phenylene)bis(phosphonate) (7). To a solution of $N^{1}, N^{4}$-diphenylbenzene-1,4diamine (5) (130 mg, $0.5 \mathrm{mmol}$ ) in NMP (5 mL) was added $\left(\mathrm{NH}_{4}\right)_{2} \mathrm{~S}_{2} \mathrm{O}_{8}(342 \mathrm{mg}, 1.5 \mathrm{mmol})$ at room temperature. After stirring for $1.5 \mathrm{~h}$, the deionized water $(90 \mu \mathrm{L}, 5.0 \mathrm{mmol})$ and $\mathrm{P}(\mathrm{OEt})_{3}$ (2.60 $\mathrm{mL}, 15.5 \mathrm{mmol}$ ) were added to the mixture at room temperature. After stirring at room temperature for $2 \mathrm{~h}$, the reaction mixture was poured into $\mathrm{H}_{2} \mathrm{O}(200 \mathrm{~mL})$. The products were extracted with $\mathrm{Et}_{2} \mathrm{O}$ three times and EtOAc twice. The combined organic layer was washed with brine and dried with $\mathrm{Na}_{2} \mathrm{SO}_{4}$. The solvents were evaporated to give the crude products, which were purified by silica-gel column chromatography (hexane/EtOAc $=7 / 3$ for $6,4 / 6$ for 7 ) to give the products $6(69 \mathrm{mg}$, $0.18 \mathrm{mmol}, 35 \%$ yield) and 7 (59 $\mathrm{mg}, 0.11 \mathrm{mmol}, 22 \%$ yield). The product 7 included a small amount of some impurities, therefore a part of 7 was further purified by preparative TLC (hexane/acetic acid $=2 / 8$ ) to give pure 7. 6: ${ }^{1} \mathrm{H}$ NMR (DMSO- $\left.d_{6}, 400 \mathrm{MHz}\right) \delta 8.12$ (s, 1H), $7.91(\mathrm{~s}, 1 \mathrm{H}), 7.33-7.19(\mathrm{~m}, 7 \mathrm{H}), 7.01(\mathrm{~d}, J=7.8 \mathrm{~Hz}, 2 \mathrm{H})$, $6.97(\mathrm{~d}, J=7.8 \mathrm{~Hz}, 2 \mathrm{H}), 6.87(\mathrm{t}, J=7.3 \mathrm{~Hz}, 1 \mathrm{H}), 6.79(\mathrm{t}, J=7.3 \mathrm{~Hz}$, 1H), 4.09-3.95 (m, 4H), 1.19 (t, $J=7.3 \mathrm{~Hz}, 6.9 \mathrm{~Hz}, 6 \mathrm{H}) ;{ }^{13} \mathrm{C}$ NMR (100 MHz, DMSO- $\left.d_{6}\right) \delta 143.91,143.27,139.37$ (d, $J=6.7 \mathrm{~Hz}$ ), $136.43(\mathrm{~d}, J=16.3 \mathrm{~Hz}), 132.75,121.83$ (d, $J=8.6 \mathrm{~Hz}), 129.36$, 129.24, 120.42, 119.82 (d, $J=13.4 \mathrm{~Hz}$ ), 119.27, 117.14, 115.78, $115.67(\mathrm{~d}, J=180.2 \mathrm{~Hz}), 62.02(\mathrm{~d}, J=4.8 \mathrm{~Hz}), 16.07(\mathrm{~d}, J=6.7 \mathrm{~Hz})$; ${ }^{31}$ P NMR (162 MHz, DMSO- $\left.d_{6}\right) \delta 20.10$; IR (KBr) $\nu$ 3303, 2980, 1599, 1496, 147, 1449, 1390, 1305, 1245-1207, 1154, 1019, 968, 747, 693 $\mathrm{cm}^{-1}$; HRMS (FAB) $m / z$ calcd for $\mathrm{C}_{22} \mathrm{H}_{25} \mathrm{~N}_{2} \mathrm{O}_{3} \mathrm{P}\left[(\mathrm{M}+\mathrm{H})^{+}\right] 396.1603$, found 396.1608. 7: ${ }^{1} \mathrm{H} \mathrm{NMR}\left(\mathrm{CD}_{2} \mathrm{Cl}_{2}, 400 \mathrm{MHz}\right) \delta 8.69(\mathrm{~s}, 2 \mathrm{H}), 7.42$ (dd, $J=3.3,4.0 \mathrm{~Hz}, 2 \mathrm{H}), 7.26-7.22(\mathrm{~m}, 4 \mathrm{H}), 7.02-6.98(\mathrm{~m}, 4 \mathrm{H})$, 6.92-6.89 (m, 2H), 4.17-4.05 (m, 8H), 1.27 (t, J=7.1 Hz, $2 \mathrm{H}) ;{ }^{13} \mathrm{C}$ NMR (150 MHz, $\left.\mathrm{CD}_{2} \mathrm{Cl}_{2}\right) \delta 143.77,143.61(\mathrm{t}, J=10.4 \mathrm{~Hz}), 129.66$, $125.38(\mathrm{t}, J=5.8 \mathrm{~Hz}), 118.28(\mathrm{dd}, J=9.3,186.7 \mathrm{~Hz}), 62.91(\mathrm{brs})$, $16.40(\mathrm{t}, J=2.9 \mathrm{~Hz}) ;{ }^{31} \mathrm{P} \mathrm{NMR}\left(162 \mathrm{MHz}, \mathrm{CD}_{2} \mathrm{Cl}_{2}\right) \delta 17.83 ; \mathrm{IR}(\mathrm{KBr}) \nu$ 3244, 2927, 1603, 1498, 1451, 1308, 1236, 1156, 1032, 969, 748, 692 $\mathrm{cm}^{-1}$; HRMS (FAB) $\mathrm{m} / z$ calcd for $\mathrm{C}_{26} \mathrm{H}_{34} \mathrm{~N}_{2} \mathrm{O}_{6} \mathrm{P}_{2}\left[(\mathrm{M}+\mathrm{H})^{+}\right]$ 532.1892, found 532.1899.

\subsection{ICP-AES analysis}

The weighed sample was diluted with concentrated nitric acid in a measuring flask. Quantification was carried out using the calibration curve, which was prepared using four points of the diluted phosphorus standard solution $(0,5,10,50 \mathrm{ppm}$ of $\mathrm{P})$.

\subsection{ESR measurements}

To ESR tubes was added a solid of PhosPANIs $\mathbf{2 b}$ and $\mathbf{2 c}$, and PMAP under air. The spectra were recorded at room 
temperature. The $g$-values were calculated based on calibration using 1,3-bisdiphenylene-2-phenylallyl (BDPA, $g=2.002756$ ) as an external standard.

\subsection{X-ray photoelectron spectroscopy (XPS) measurements}

The sample film was prepared from a deionized water/THF $=2$ / $1(\mathrm{v} / \mathrm{v})$ suspension of PhosPANI $2 \mathbf{b} .13 \mu \mathrm{L}$ of the suspension was dropped onto a piece of clean silver plate before drying it under reduced pressure $\left(40{ }^{\circ} \mathrm{C}\right.$ through overnight). After the sample plate was fixed onto a sample holder, it was put into an ultrahigh-vacuum chamber $\left(1-2 \times 10^{-6} \mathrm{~Pa}\right)$ at room temperature. The $\mathrm{Al}_{\mathrm{K} \alpha}$ line $(1486.6 \mathrm{eV})$ was chosen as an X-ray source. The tube current was $25.0 \mathrm{~mA}$, the tube voltage was $12.0 \mathrm{kV}$ and the pass energy was $50 \mathrm{eV}$. The surface of the sample film was cleaned by argon-ion etching for $30 \mathrm{~s}$ before recording the spectra. During the etching process, the pressure of argon gas was kept to be $\sim 4 \times 10^{-4} \mathrm{~Pa}$. The accelerating voltage of the ion gun was $400 \mathrm{~V}$ and the current was $6.4 \mathrm{~mA}$. In addition to $\mathrm{N} 1 \mathrm{~s}$ spectra, Ag 3d spectra were also measured as a reference. The spectra were accumulated nine times (for $\mathrm{N}$ 1s) or eight times (for $\mathrm{Ag} \mathrm{3d}$ ). The obtained spectra were analyzed using an analysis software (Light Stone, OriginPro 2015J Student Version 64Bit). For quantitative analysis, the peak intensity (counts/sec) was corrected using appropriate transmission values supplied by the instrument manufacturer. The accumulated spectra were smoothed by Savitzky-Golay method. The points of window were 50 (for $\mathrm{N} 1 \mathrm{~s}$ ) or 30 (for $\mathrm{Ag} 3 \mathrm{~d}$ ), boundary condition was none and polynomial order was 2. After the spectra were compensated by subtracting linear function to remove their gradient, the background of the spectra was subtracted using Shirley method. In deconvoluting the spectra, they were fitted with Voigt functions, where Lorentzian width was fixed to $0.25 \mathrm{eV}$.

\subsection{Absorption spectrum measurements}

A glass substrate $(26 \times 13 \mathrm{~mm})$ was ultrasonically washed with solvents in order of neutral detergent, desalted water, acetone, ethanol and desalted water twice. The glass substrate was cleaned by $\mathrm{UV}-\mathrm{O}_{3}$ treatment $(12 \mathrm{~W}$ low pressure mercury lamp, flowing air) for $1 \mathrm{~min}$ after drying. The suspension of PhosPANIs 2 (1 mg) in $0.1 \mathrm{~mL}$ of methanolic aqueous $\mathrm{NH}_{3}$ solution $\left(\mathrm{MeOH} / \mathrm{H}_{2} \mathrm{O} / 0.15 \mathrm{M}\right.$ aqueous $\mathrm{NH}_{3}$ solution $\left.=1 / 1 / 1 \mathrm{v} / \mathrm{v}\right)$ was dropped onto the glass substrate, which was dried at $100{ }^{\circ} \mathrm{C}$ for $3 \mathrm{~min}$. The obtained films were used for the absorption measurements.

\subsection{Sheet resistance measurements}

An interdigitated array platinum electrode composed of 65 pairs (width between electrodes $=3 \mu \mathrm{m}$, length $=2.4 \mathrm{~mm}$ ) [IDA electrode (Pt) from ALS Co., Ltd, see also http://www.alsjapan.com/support-ida.html] was used to measure the sheet resistance by a direct-current method. The suspension of PhosPANIs $2\left(10 \mathrm{~g} \mathrm{~L}^{-1}\right)$ in methanolic aqueous $\mathrm{NH}_{3}$ solution $\left(\mathrm{MeOH} / \mathrm{H}_{2} \mathrm{O} / 0.15 \mathrm{M}\right.$ aqueous $\mathrm{NH}_{3}$ solution $\left.=1 / 1 / 1 \mathrm{v} / \mathrm{v}\right)$ was dropped onto the electrode, which was dried at $100{ }^{\circ} \mathrm{C}$ for $2 \mathrm{~min}$.
The measurements of the electrical resistance for a two-probe method were conducted under environmental conditions.

\section{Results and discussion}

\subsection{Synthesis}

According to several reports on the nucleophilic substitution of PANI, ${ }^{\text {24-27 }}$ PANI (emeraldine base) 1 was treated with an excess amount of $\mathrm{P}(\mathrm{OEt})_{3}$ as a nucleophile in the presence of $\mathrm{H}_{2} \mathrm{O}$ in NMP at room temperature. The reaction was followed with UVvis-NIR absorption spectroscopy by taking a small amount of the sample from the reaction mixture. However, no reaction was suggested (Scheme 2a-I). To improve the electrophilicity of PANI, PANI (emeraldine base) 1 was oxidized by $\left(\mathrm{NH}_{4}\right)_{2} \mathrm{~S}_{2} \mathrm{O}_{8}$ in NMP to give 4. Then, $\mathrm{P}(\mathrm{OEt})_{3}$ (5 equivalents to the aniline unit) and $\mathrm{H}_{2} \mathrm{O}$ were added to the mixture at room temperature (Scheme 2a-II). The reaction was also followed by UV-vis-NIR absorption spectroscopy (Fig. S1 $\dagger$ ). After the treatment of PANI (emeraldine base) with $\left(\mathrm{NH}_{4}\right)_{2} \mathrm{~S}_{2} \mathrm{O}_{8}$, a typical spectrum for PANI (oxidized form) 4 with a peak around $550 \mathrm{~nm}$ appeared (Fig. S1 $\dagger) .{ }^{33}$ The addition of $\mathrm{P}(\mathrm{OEt})_{3}$ to the mixture induced the spectral change to give a peak at $619 \mathrm{~nm}$, which is assignable to the charge transfer band for PANI (emeraldine base). ${ }^{33}$ The reaction mixture was poured into $\mathrm{H}_{2} \mathrm{O}$ after checking that there were no more changes in the spectrum. The resultant precipitate was collected and washed with an ammonia solution for dedoping. The ICP-AES analysis indicated that the formal substitution ratio of phosphonate to the total number of phenyl rings in the polymer is estimated to be approximately $33 \%$. The thus-obtained diethylphosphonated PANIs 3 are described as EtPhosPANIs $3(X \% \mathrm{P}, X=$ the formal substitution ratio of phosphonate). The yield of the EtPhosPANI 3a (33\% P) was $84 \%$ (Scheme 2a-II). The chemical shift of phosphorus in ${ }^{31} \mathrm{P}$ NMR for the obtained compound appeared at 17.3-20.3 ppm, which is in a range for arylphosphonates (Fig. S2 $\dagger$ ). Thus, carbonphosphorus bond formation was confirmed. ${ }^{1} \mathrm{H}$ NMR also showed the presence of the ethyl group derived from the ethylphosphonate (Fig. S3 $\dagger$ ). Proposed mechanistic pathway of the reaction is shown in Scheme $\mathrm{S} 1 \mathrm{a} . \dagger$

The equivalents of $\mathrm{P}(\mathrm{OEt})_{3}$ and temperature were investigated to improve the substitution ratio of phosphonate (Table $\mathrm{S} 1 \dagger)$. Use of 0.75 equivalents of $\mathrm{P}(\mathrm{OEt})_{3}$ resulted in $9 \%$ substitution ratio (Table $\mathrm{S} 1, \dagger$ entry 1 ). The more equivalents of $\mathrm{P}(\mathrm{OEt})_{3}$, the more substitution ratio was attained. Raise in the temperature to $60{ }^{\circ} \mathrm{C}$ induced the substitution ratio as well. The optimized conditions are use of 7.8 equivalents of $\mathrm{P}(\mathrm{OEt})_{3}$ at $60{ }^{\circ} \mathrm{C}$, where the substitution ratio and yield of EtPhosPANI $3 \mathbf{b}$ (52\% P) were $52 \%$ and $77 \%$, respectively (Scheme $2 \mathrm{a}-\mathrm{III}$ and entry 6 in Table S1†). Gram scale synthesis was possible. Instead of $\mathrm{P}(\mathrm{OEt})_{3}$, use of $\mathrm{HPO}(\mathrm{OEt})_{2}$ did not afford EtPhosPANI 3.

Further phosphonation of EtPhosPANI $3 \mathbf{b}(52 \% \mathrm{P})$ was carried out by repeating the procedure consisted of the oxidation and reductive phosphonation to give EtPhosPANI 3c (73\% P) (Scheme 2a-IV). Thus, the substitution ratio increased up to $73 \%$.

Hydrolysis of EtPhosPANIs $3 \mathbf{b}(52 \% \mathrm{P})$ and $3 \mathbf{c}(73 \% \mathrm{P})$ was performed by treating with $\mathrm{Me}_{3} \mathrm{SiBr}$, followed by pouring into 

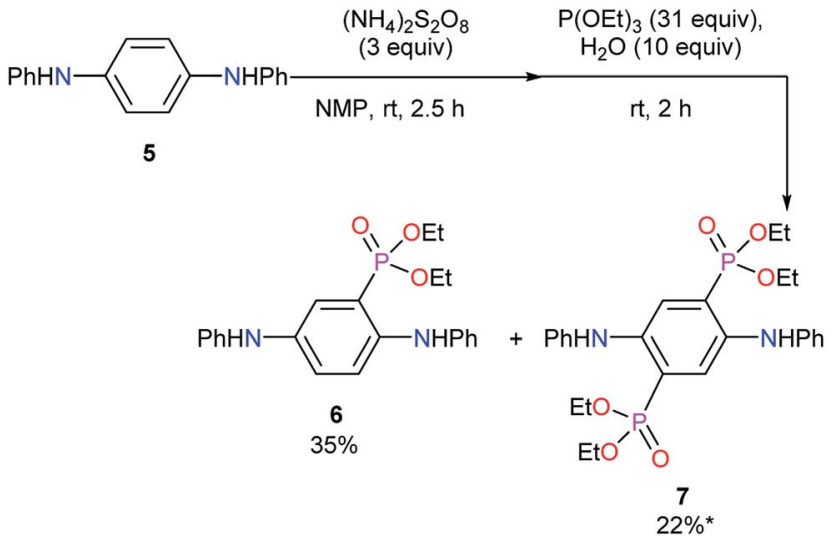

Scheme 3 Model reaction for phosphonation reaction using diamine 5. *Including a small amount of impurity.

$\mathrm{H}_{2} \mathrm{O}$ to give a precipitate (Scheme $2 \mathrm{~b}$ ). ${ }^{34}$ Washing the precipitate with $\mathrm{Et}_{2} \mathrm{O}$ gave the corresponding PhosPANIs $2 \mathbf{b}$ and $2 \mathbf{c}$ as a black solid. The completing of the hydrolysis was confirmed with the disappearance of the peaks for ethyl groups in the ${ }^{1} \mathrm{H}$ NMR spectra. PhosPANIs $\mathbf{2 b}$ and $2 \mathbf{c}$ were comparatively soluble in aqueous basic solution, but their solubility was low in organic solvents and neutral to acidic aqueous solutions.
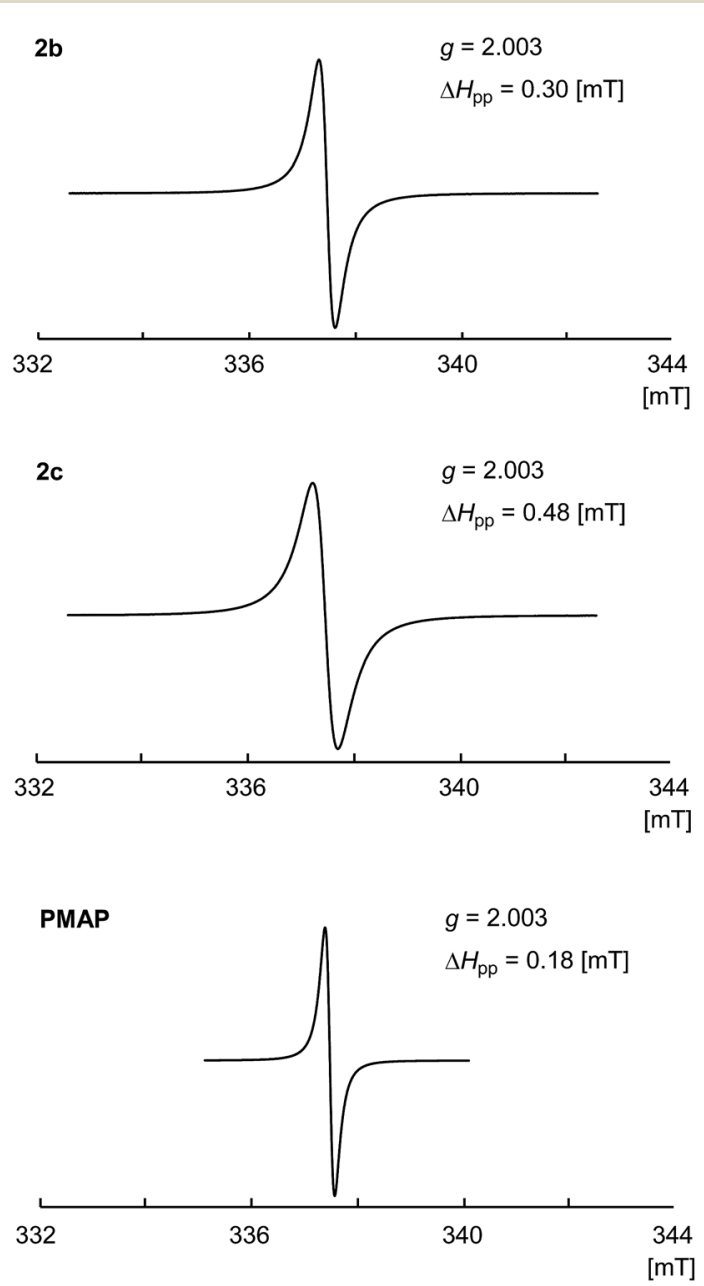

Fig. 2 ESR spectra for PhosPANIs $2 \mathrm{~b}$ and $2 \mathrm{c}$, and PMAP.
To collect the information for the substitution reaction, the model reaction using $N^{1}, N^{4}$-diphenylbenzene-1,4-diamine (5) was carried out. In the similar conditions to synthesize 3 , monodiethylphosphonated product 6 and bis-diethylphosphonated product 7 were obtained in $35 \%$ and $22 \%$ yields, respectively (Scheme 3). The oxidative poly- or oligomerization of 5 was also suggested in this reaction, resulting in the low mass balance. Di-substituted compound 7 is considered to be formed via double 1,4-addition and the subsequent aromatization by aerobic oxidation (Scheme $\mathrm{S} 1 \mathrm{~b} \dagger$ ). The similar reported reaction using 1,4-benzoquinone supports the reaction path. ${ }^{35}$ Partial disubstitution in the obtained EtPhosPANIs 3 is expected from these results. The chemical shift of phosphorus in ${ }^{31} \mathrm{P}$ NMR of 6 and 7 were 20.1 and $18.8 \mathrm{ppm}$, respectively. These data support the carbon-phosphorus bond in EtPhosPANIs 3.

\subsection{ESR properties}

The solid state ESR spectra of the obtained PhosPANIs $\mathbf{2 b}$ and 2c, and PMAP are shown in Fig. 2. Single resonance lines centered on around $g=2.003$ without hyperfine coupling were observed for $\mathbf{2 b}$ and $2 \mathbf{c}$, and PMAP. The obtained spectra are characteristic of related conducting PANIs, ${ }^{36}$ indicating that their self-doping. The peak-to-peak line width $\Delta H_{\mathrm{pp}}$ has been used to estimate the level of delocalization of electrical charge carrier in PANI, where the smaller $\Delta H_{\mathrm{pp}}$ shows more efficient delocalization. ${ }^{37}$ The $\Delta H_{\mathrm{pp}}$ for $2 \mathbf{b}$ and $2 \mathbf{c}$ was 0.30 and $0.48 \mathrm{mT}$, respectively, which are larger than that of the solid state ESR for $\operatorname{PMAP}\left(\Delta H_{\mathrm{pp}}=0.18 \mathrm{mT}\right)$. These results suggest that the polaron of PhosPANIs $\mathbf{2 b}$ and $2 \mathbf{c}$ is less delocalized than that of PMAP.

\subsection{Doping efficiency}

Doping efficiency of PhosPANI $2 \mathbf{b}$ was investigated by the XPS experiment (Fig. 3). The N 1s core-level spectrum was fitted with

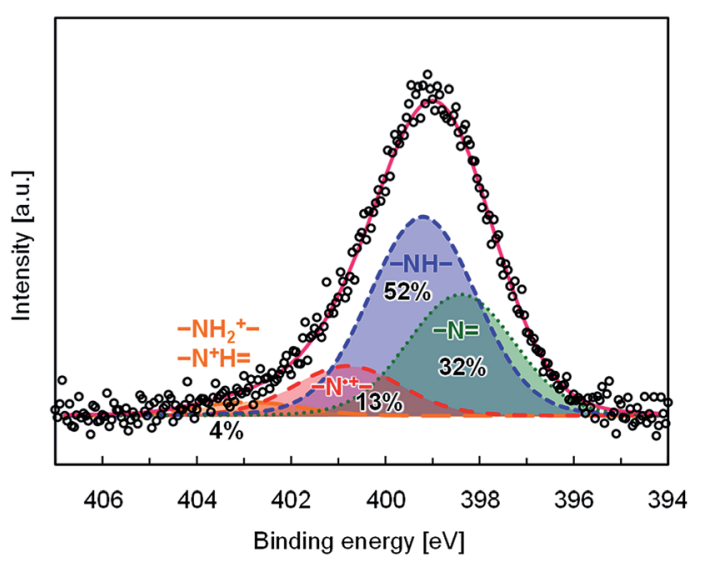

Fig. $3 \mathrm{~N}$ 1s XPS spectrum for PhosPANI $2 \mathrm{~b}$ with its deconvoluted spectra; white circle (O): raw data, red solid line (-): convoluted spectrum, orange long dashed line $(--)$ : protonated $\left(-\mathrm{NH}_{2}{ }^{+}-\right.$, $-\mathrm{N}^{+} \mathrm{H}=$ ) nitrogen, red dashed line $(---)$ : radical cation $\left(-\mathrm{N}^{\cdot+}-\right)$ nitrogen, blue dashed line (----): neutral amine $(-\mathrm{NH}-)$ nitrogen and green dot line ( . . . .): neutral imine $(-\mathrm{N}=)$ nitrogen. Binding energy was calibrated using the $\mathrm{Ag} 3 \mathrm{~d}_{5 / 2}$ peak as $368.2 \mathrm{eV}$. The spectra are shown here after subtracting its background. 
four components, which were attributed to protonated $\left(-\mathrm{NH}_{2}{ }^{+}-\right.$, $\left.-\mathrm{N}^{+} \mathrm{H}=\right)$, radical cation $\left(-\mathrm{N}^{\cdot+}-\right)$, neutral amine $(-\mathrm{NH}-)$ and imine $(-\mathrm{N}=)$ nitrogen sites at 402.4, 400.4, 398.8 and $398.0 \mathrm{eV}$, respectively. The peak positions were comparable to the previously reported ones. ${ }^{38}$ The area ratio for the nitrogen atoms is summarized in Fig. 3. The doping level corresponds to the area ratio for the radical cation nitrogen $\left(-\mathrm{N}^{+}-\right)$sites, which was $13 \%$. This value is lower than that for PMAP. ${ }^{28}$ This is consistent with the results of the ESR experiments. One of the major reasons is that the substitution ratio of the phosphonic acid moiety is low.

\subsection{Electronic absorption}

Electronic absorptions for the films of PhosPANIs 2 were investigated (Fig. 4). The film of $\mathbf{2 b}$ was formed on a glass substrate by drop-cast of aqueous $\mathrm{NH}_{3} / \mathrm{MeOH}$ suspension of $\mathbf{2 b}$ followed by annealing at $100{ }^{\circ} \mathrm{C}$ for $2 \mathrm{~min}$. The absorption spectrum of the thus-obtained film of $2 \mathbf{b}$ showed a broad peak around $450 \mathrm{~nm}$ assigned as a polaron band ${ }^{39}$ and broad one from $600 \mathrm{~nm}$ (Fig. 4a). The broad absorption from $600 \mathrm{~nm}$ is considered to include CT transition (around $600 \mathrm{~nm}$ ), further localized polaron band (around $750 \mathrm{~nm})^{39}$ and free carrier tail (>around $1000 \mathrm{~nm}$ ). ${ }^{39}$ Absorptions of polaron and CT transition indicate the doped and de-doped states, respectively. Thus, both self-doped and de-doped moieties seem to be present in PhosPANI $2 \mathbf{b}$. Despite the use of basic aqueous suspension of $\mathbf{2 b}$ to form the film (absorption spectra for the suspension clearly showed the complete dedoping, see Fig. $\mathrm{S} 4 \dagger$ ), the reason that the complete de-doping was not observed for the film can be explained by removal of $\mathrm{NH}_{3}$ under annealing conditions. Fig. $4 \mathrm{~b}$ shows the spectra of similarly prepared films for $\mathbf{2 c}$. The spectrum for $\mathbf{2 c}$ exhibits the

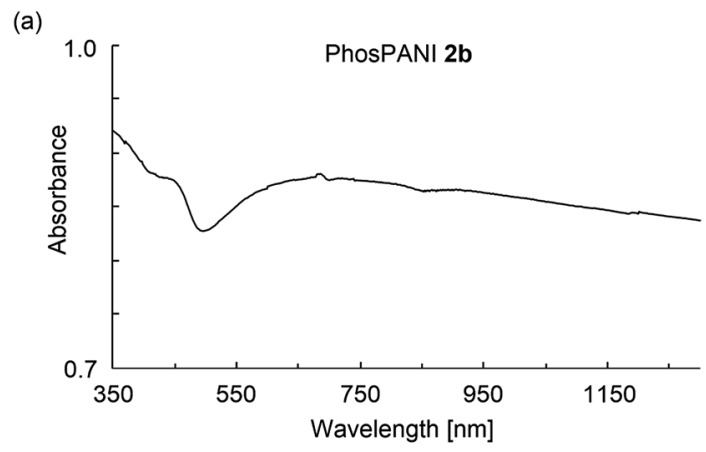

(b)

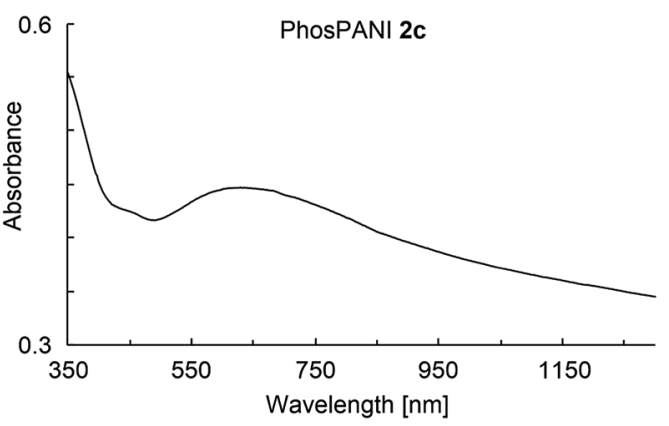

Fig. 4 UV-vis-NIR absorption spectra for the drop-cast films of the aqueous $\mathrm{NH}_{3} / \mathrm{MeOH}$ suspension of (a) PhosPANIs $2 \mathrm{~b}$ and (b) $2 \mathrm{c}$. small broad peak for polaron (around $420 \mathrm{~nm}$ ) and large and broad peak for the CT transition and further localized polaron band (around $700 \mathrm{~nm}$ ), suggesting the partial doping and less delocalization of polaron. This is consistent with the result of the large $\Delta H_{\mathrm{pp}}$ in ESR spectrum of $2 \mathrm{c}$.

\subsection{Electrical conductive property}

Electrical conductive properties of PhosPANIs $\mathbf{2 b}$ and $2 \mathbf{c}$ were investigated in terms of sheet resistance of the drop-cast film. Sheet resistance of PMAP was also measured for comparison. An interdigitated array platinum electrode was used to measure the sheet resistance by a direct-current method. The $c a .10 \mathrm{~g} \mathrm{~L}^{-1}$ aqueous $\mathrm{NH}_{3} / \mathrm{MeOH}$ suspensions of PhosPANIs $2 \mathbf{b}$ and $2 \mathbf{c}$ were drop-casted on the electrode. The sheet resistances of PhosPANIs $2 \mathbf{b}$ and 2 c, and PMAP were $3.6 \times 10^{9}, 4.0 \times 10^{10}$ and $2.2 \times$ $10^{7} \Omega$ per square at room temperature, respectively. The magnitude of the sheet resistance is a level for charge dissipation materials. ${ }^{40}$ The lower conductive property of $2 \mathrm{c}$ was observed despite the more substituted ratio of phosphonic acid moiety. However, it is consistent with the results of the ESR and absorption spectra. The conductive property of PMAP is two order of magnitude higher than that of $\mathbf{2 b}$, which might be due to the more efficient doping in PMAP. The conductive properties of $\mathbf{2 b}$ and $\mathbf{2 c}$ seem to be lower than the externally doped PANI with phosphonic acid. ${ }^{41}$ It might be considered that introduction of the substituent induces twist of the main chain of PANI and the effective conjugation length becomes short.

\section{Conclusions}

Phosphonic acid ring-substituted PANIs, PhosPANIs 2, were synthesized via reductive phosphonation of pernigraniline (fully oxidized form of PANI) with $\mathrm{P}(\mathrm{OEt})_{3}$ and the subsequent hydrolysis. This is the first example of the direct phosphonation of PANI. The formal substitution ratio of the phosphonate to the total number of phenyl rings in the polymer after the phosphonation reaction was up to $52 \%$. The repetition of the phosphonation reaction procedure gave EtPhosPANI 3c (73\% P) with $73 \%$ substitution ratio. Hydrolysis of EtPhosPANIs 3 afforded the desired PhosPANIs 2 . The self-doping of the obtained PhosPANIs 2 was clearly exhibited by ESR, XPS and UVvis-NIR absorption spectroscopy. The drop-casted films of PhosPANIs 2 showed electrical conductive property with a level for charge dissipation materials. The developed synthetic approach is considered to be valuable as a practical method for phosphonic acid self-doped conductive PANIs.

\section{Acknowledgements}

We thank Dr Ichiro Hisaki for the experiments of TGA. We thank the members of the Comprehensive Analysis Center, ISIR, Osaka University, for ICP-AES and XPS measurements. This work was partially supported by Matching Planner Program (MP27115658604) from Japan Science and Technology Agency (JST). 


\section{Notes and references}

1 A. G. MacDiarmid, Angew. Chem., Int. Ed., 2001, 40, 25812590.

2 K. Lee, S. Cho, S. H. Park, A. J. Heeger, C.-W. Lee and S.-H. Lee, Nature, 2006, 441, 65-68.

3 P. Lin and F. Yan, Adv. Mater., 2012, 24, 34-51.

4 G. Ćirić-Marjanović, Synth. Met., 2013, 177, 1-47.

5 J. F. Mike and J. L. Lutkenhaus, ACS Macro Lett., 2013, 2, 839844.

6 P. P. Deshpande, N. G. Jadhav, V. J. Gelling and D. Sazou, J. Coat. Technol. Res., 2014, 11, 473-494.

7 L. Xu, L. Cheng, C. Wang, R. Peng and Z. Liu, Polym. Chem., 2014, 5, 1573-1580.

8 A. Malinauskas, J. Power Sources, 2004, 126, 214-220.

9 M. S. Freund and B. Deore, Self-Doped Conducting Polymers, John Wiley \& Sons, Ltd., New York, 2007.

10 J. Yue and A. J. Epstein, J. Am. Chem. Soc., 1990, 112, 28002801.

11 X.-L. Wei, Y. Z. Wang, S. M. Long, C. Bobeczko and A. J. Epstein, J. Am. Chem. Soc., 1996, 118, 2545-2555.

12 H. S. O. Chan, S. C. Ng, A. S. Sim, K. L. Tan and B. T. G. Tan, Macromolecules, 1992, 25, 6029-6034.

13 S. C. Ng, H. S. O. Chan, H. H. Huan and P. K. H. Ho, J. Chem. Soc., Chem. Commun., 1995, 1327-1328.

14 S. Shimizu, T. Saitoh, M. Uzawa, M. Yuasa, K. Yano, T. Maruyama and K. Watanabe, Synth. Met., 1997, 85, 1337-1338.

15 H. S. O. Chan, A. J. Neuendorf, S.-C. Ng, P. M. L. Wong and D. J. Young, Chem. Commun., 1998, 1327-1328.

16 M. Nicolas, B. Fabre, G. Marchand and J. Simonet, Eur. J. Org. Chem., 2000, 1703-1710.

17 T. Amaya, Y. Abe, Y. Inada and T. Hirao, Tetrahedron Lett., 2014, 55, 3976-3978.

18 T. Amaya, Y. Abe, Y. Inada and T. Hirao, Synth. Met., 2014, 195, 137-140.

19 Y. Abe, T. Amaya and T. Hirao, Bull. Chem. Soc. Jpn., 2014, 87, 1026-1028.

20 P. Hany, E. M. Geniès and C. Santier, Synth. Met., 1989, 31, 369-378.

21 J.-Y. Bergeron, J.-W. Chevalier and L. H. Dao, J. Chem. Soc., Chem. Commun., 1990, 180-182.

22 C. DeArmitt, S. P. Armes, J. Winter, F. A. Uribe, S. Gottesfeld and C. Mombourquette, Polymer, 1993, 34, 158-162.

23 S. A. Chen and G. W. Hwang, J. Am. Chem. Soc., 1994, 116, 7939-7940.
24 C.-C. Han and R.-C. Jeng, J. Chem. Soc., Chem. Commun., 1997, 553-554.

25 H. Salavagione, G. M. Morales, M. C. Miras and C. A. Barbero, Acta Polym., 1999, 50, 40-44.

26 C.-C. Han, C.-H. Lu, S.-P. Hong and K.-F. Yang, Macromolecules, 2003, 36, 7908-7915.

27 For a review: M. C. Miras, D. F. Acevedo, N. Monge, E. Frontera, C. R. Rivarola and C. A. Barbero, Open Macromol. J., 2008, 1, 58-73.

28 Y. Abe, T. Amaya, Y. Inada and T. Hirao, Synth. Met., 2014, 197, 240-245.

29 T. Amaya, Y. Abe, H. Yamamoto, T. Kozawa and T. Hirao, Synth. Met., 2014, 198, 88-92.

30 T. Amaya, Y. Abe and T. Hirao, Macromolecules, 2014, 47, 8115-8188.

31 T. Amaya, R. Sugihara, D. Hata and T. Hirao, $R S C A d v ., 2016$, 6, 22447-22452.

32 J. F. Moulder, W. F. Stickle, P. E. Sobol and K. D. Bomben, Handbook of X-ray Photoelectron Spectroscopy, Perkin-Elmer Corporation, Eden Prairie, MN, 1992.

33 E. T. Kang, K. G. Neoh and K. L. Tan, Prog. Polym. Sci., 1998, 23, 277-324.

34 Related conditions for hydrolysis: C. Cheng, Y. Liu, M. E. Balasis, N. L. Simmons, J. Li, H. Song, L. Pan, Y. Qin, K. C. Nicolaou, S. M. Sebti and R. Li, Mar. Drugs, 2014, 12, 1335-1348.

35 B. Xiong, R. Shen, M. Goto, S.-F. Yin and L.-B. Han, Chem.Eur. J., 2012, 18, 16902-16910.

36 L. Dennany, P. C. Innis, F. Masdarolomoor and G. G. Wallace, J. Phys. Chem. B, 2010, 114, 2337-2341.

37 Z. H. Wang, E. M. Scherr, A. G. MacDiarmid and A. J. Epstein, Phys. Rev. B: Condens. Matter Mater. Phys., 1992, 45, 41904202.

38 The peak positions $(402.4,400.4,398.8$ and $398.0 \mathrm{eV})$ shifted downward by $\sim 0.2 \mathrm{eV}$ compared to those in the previous report (402.6, 400.6, 399.0 and $398.2 \mathrm{eV}$ ). This could be arisen from charge up on the measured region because the degree of charge was different between the PhosPANI $2 \mathbf{b}$ film and the silver plate.

39 Y. Xia, J. M. Wiesinger and A. G. MacDiarmid, Chem. Mater., 1995, 7, 443-445.

40 J. Markarian, Plast. Addit. Compd., 2008, 10, 22-25.

41 In the following reference, electrical conductive property was shown as a volume conductivity. So, it was judged from comparison with volume conductivity of PMAP (see ref. 17). H. S. O. Chan, S. C. $\mathrm{Ng}$ and P. K. H. Ho, Macromolecules, 1994, 27, 2159-2164. 